\title{
UNA MIRADA AL MUNDO ÉTICO DE LA VIDA A PARTIR DE LA EXPERIENCIA DEL DOLOR CLÍNICO
}

\section{A VIEW OF THE ETHICAL LIFEWORLD FROM EXPERIENCE OF CLINICAL PAIN}

\author{
Luis Guillermo Jaramillo' ${ }^{1}$ Juan Carlos Aguirre²
}

1Doctor en Ciencias Humanas y Sociales - Educación, Universidad del Cauca Ciudadela Campestre La Rioja, Casa i-2 Popayán, Cauca, Colombia. E-mail: ljaramillo@unicauca.edu.co 2Magíster en Filosofía, Universidad del Cauca Ciudadela Campestre La Rioja, Casa i-7 Popayán, Cauca, Colombia. E-mail: jcaguirre@unicauca.edu.co.

Rev. U.D.C.A Act. \& Div. Cient. 15(1): 9 - 17, 2012

\section{RESUMEN}

El artículo explora el fenómeno del dolor a la luz de las consideraciones éticas de Emmanuel Levinas. Para ello, se exponen algunos postulados fenomenológicos acerca del mundo de la vida; posteriormente, se despliega la propuesta de la conciencia no-intencional vista en relación con el fenómeno del dolor y, finalmente, tanto la tesis del mundo de la vida como la de la conciencia no-intencional sirven como soportes para analizar el fenómeno del dolor clínico. El artículo presenta unas conclusiones que permitirán reflexionar sobre la ética médica frente al dolor, en el mundo de la vida.

Palabras clave: Dolor, paciente, empatía, comunicación, conciencia.

\section{SUMMARY}

This paper explores the phenomena of pain based on the ethical considerations of Emmanuel Levinas. For this purpose, some phenomenological postulates about the world of life are exposed; later, the proposal of the non-intentional consciousness in relation with the phenomena of pain is unfolded; finally, both the thesis of world of life as the nonintentional thesis are considered useful as base to analyze the clinical phenomena of pain. This article presents some conclusions that allow to reflect about the medical ethics in front of pain in the world of life.

Key words: Pain, patient, empathy, communication, consciousness.

\section{INTRODUCCIÓN: LEBENSWELT O MUNDO DE LA VIDA}

Antes de establecer la relación entre Lebenswelt o Mundo de la vida y Ética de la vida es preciso enmarcar la Lebenswelt dentro del pensamiento del fenomenólogo Edmund Husserl, toda vez que es, en este marco, donde tendrá lugar la presente discusión. No se hará una exégesis detallada del concepto, sino que se resaltarán los puntos a los que se aludirá con mayor énfasis; tampoco se agotará la literatura sobre el tema, la cual, es bastante amplia (a modo de ejemplo, los trabajos de Gadamer, 1993; Habermas, 1987; Ströker, 1997; Iribarne, 2008; Walton, 1993), sino que nos limitaremos al parágrafo 10 de "Experiencia y Juicio" (Husserl, 1980), titulado: "El retroceso a la evidencia de la experiencia como retroceso al mundo vital [Lebenswelt]. Destrucción de las idealizaciones que cubren el mundo vital". Valga aclarar que Husserl (2008b) abordó con detalle y sumo cuidado estas cuestiones.

Al fenomenólogo le interesa indagar acerca de los cimientos de la experiencia, tratando de buscar cómo tal experiencia se da a nosotros de manera evidente, es decir, clara, sin lugar a dudas. Es sabido que todo conocimiento evidente adquiere la forma de una proposición, Husserl habla de juicios predicativos o enunciados afirmativos, en otras palabras, la forma $\mathrm{S}$ es $\mathrm{P}$, donde $\mathrm{S}$ es el sujeto y $\mathrm{P}$ el predicado; por ejemplo: Juan está enfermo, María cuida a sus pacientes. Esos enunciados alcanzan su plena exposición cuando se enuncian como "juicios". Ahora bien, la búsqueda que inicia el fenomenólogo se dirige a dejar clara la relación entre lo que se afirma en $\mathrm{P}$ acerca de $\mathrm{S}$, o sea, la forma como el juicio se relaciona con la experiencia que enuncia; en definitiva, cuál es el suelo del que brota el juicio. 
Hablar de suelo es plantear la premisa que, a lo largo de los años, los juicios han ido acumulando sentidos que es preciso develar si se quiere encontrar cuál fue la fuente de su origen. El método fenomenológico tendrá que recurrir al análisis genético, es decir, génesis u origen, de modo que se despejen las diversas idealizaciones que se han ido tejiendo alrededor de la experiencia, ocultándola o haciendo que aparezca confusa. Después de este proceso, quedaríamos con el mundo de la experiencia, con el mundo vital en el que siempre hemos vivido, en el terreno sobre el que se asienta todo conocimiento y toda ciencia.

El propio Husserl reconoce que esta tarea no es fácil, pues no se trata solamente de "remontarnos, a partir de algunos juicios particulares que podemos tener a la vista como ejemplos, a la manera como se dan previamente los objetossustratos" (Husserl, 1980), sino de comprender el complejo horizonte, en el que cada una de las funciones de experiencia, se confunden de modo inseparable. Este entretejimiento de funciones, oculto en la formulación definitiva del juicio, siempre ha estado circundándonos y nos lo hemos ido apropiando, "mediante comunicación, aprendizaje o tradición" (Husserl, 1980), en otras palabras, este mundo nos ha sido pre-dado en nuestra familiaridad y, a su vez, en él se nos ha señalado de antemano el sentido con el que todo objeto es determinable, en general, como lo-que-es.

Husserl (1980) plantea que el pre-darse de lo-que-es permite el actuar de la ciencia y sus métodos: "el estilo de esta manera de conocer se ha hecho tan paradigmático que de antemano existe la convicción de que los objetos de nuestra experiencia están determinados en sí, y que la función del conocimiento es justo descubrir en una aproximación estas determinaciones existentes en sí y fijarlas de manera "objetiva” como son en sî". Es obvio que las ciencias físico-matemáticas toman el mundo de nuestra experiencia y determinan en él lo-que-es en sí, de manera objetiva. En el mundo espacio-temporal, las ciencias experimentan y establecen leyes causales: "con la misma obviedad se presupone que el nexo causal de lo-que-es, tal como se da en la experiencia, es el mismo que se determina posteriormente con exactitud y objetividad en la ciencia objetiva, como aquel nexo a que se refieren las leyes causales exactas" (Husserl, 1980). Según lo anterior, el mundo de la experiencia se ve reflejado en las idealizaciones del mundo de la ciencia, por ejemplo, la idealización del espacio conduce al espacio exacto de la geometría; sin embargo, valga aclarar, que tales idealizaciones se basan en los datos previos de nuestra experiencia inmediata (el punto cumbre del desarrollo de esta idea se encuentra en Husserl (2008a).

Se puede decir, entonces, que el conocimiento científico hunde sus raíces en contextos vitales o mundo de la vida, como punto de partida para la elaboración de conceptos y de categorías, sobre los cuales, la ciencia dará cuenta como saber sistemático y verdadero, en otras palabras, la ciencia toma sus problemas del mundo cotidiano o cotidianidad de la vida y los resultados de ese proceso de elaboración de conocimiento nuevo se revierten sobre esas estructuras de la vida social; de este modo, podemos decir que la praxis social es génesis $y$, a la vez, punto de llegada de los procesos de investigación científica (una explicación detallada de este proceso, se encuentra en San Martín, 2010). Ahora bien, el pensamiento moderno, caracterizado por lo que Husserl llama: la matematización de la naturaleza, "sustituyó el mundo de nuestra experiencia por el mundo exacto, olvidándose completamente de preguntar por las operaciones originarias, dadoras de sentido; con ello se pasó por alto que ese método de la idealización, a fin de cuentas, no logra más que una anticipación ampliada hasta el infinito de lo que cabe esperar de la experiencia" (Husserl, 1980). Aguirre \& Jaramillo (2010a) exponen una presentación detallada de este proceso de idealización. Según ellos, la idealización es vista por Husserl como un ejercicio de arropar la experiencia cotidiana, como un cubrir la experiencia pura. Lo complejo de la situación es que cuando se intenta descubrir los fundamentos de lo que es en sí, de los fundamentos del conocer, se toma a la naturaleza arropada, idealizada, es decir, se hace uso de la arquitectónica de las ciencias, de sus proposiciones y leyes. Esto, a decir de Husserl, ha conducido al olvido de la experiencia originaria y a la entronización del conocimiento exacto, como único tipo de conocimiento posible; por ello, la formulación de la Lebenswelt es un esfuerzo de Husserl por integrar en la explicación de la naturaleza de la ciencia elementos que, de no tenerse en cuenta, conducirían a una imagen unívoca, pero irreal del fenómeno científico.

Finalmente, Husserl propugna por lo que él llama: la justificación de la doxa, lo cual, consiste en integrar el saber exacto de la ciencia y el saber de la experiencia pre-predicativa dadora desde el mundo de la vida. Doxa, en este contexto, significa "el ámbito de las evidencias últimas y originarias aún no exactas ni idealizadas físico-matemáticamente" (Husserl, 1980). Tal justificación de la doxa, necesariamente, exigirá buscar la experiencia del mundo vital, deshaciéndose, así sea metodológicamente, como cuando se practica la epojé, de las idealizaciones.

El retorno al mundo vital no es una mera defensa del empirismo ingenuo, no es una simple aceptación del mundo tal y como se nos da, sino que involucra la historicidad, durante, la cual, los sentidos se han ido sedimentando. Muy a pesar de lo que algunos creen, la Lebenswelt no es un programa que se pretenda convertir en ciencia autónoma, una especie de exclusividad de lo que Maffesoli (1993, 1997) denomina "Conocimiento Ordinario", es más bien un 
ejercicio que tiene como fin "esclarecer el camino por el que debe llegarse a las evidencias en niveles superiores y de los presupuestos ocultos en los que estas evidencias se fundan y los que determinan y limitan su sentido" (Husserl, 1980). Con base en lo anterior, podemos decir que los procesos vitales del ser humano, en este caso su salud, desbordan las pretensiones teórico-asistenciales de la ciencia médica (Gadamer, 1996); por lo general, el concepto de saludenfermedad se ha entendido como la asistencia que se dirige desde un sujeto que porta un saber especializado y exacto, hacia un otro necesitado que ignora los motivos y los orígenes de su dolor y su enfermedad. El mundo de la experiencia o mundo vital en el que el paciente siempre ha vivido, no es determinante, por cuanto se precisa un diagnóstico "veraz" acerca de la enfermedad; en tal sentido, la medicina no alcanza a comprender cómo en el complejo horizonte de las experiencias del paciente, se entretejen, de modo inseparable, unidades de sentido que dan cuenta de su enfermedad. Por el contrario, la linealidad de la ciencia médica, se asienta en la lógica de la evidencia que porta el profesional de la salud y que "suele manifestarse como un distanciamiento y objetivación del otro en la formalización del lenguaje, haciendo del otro-paciente un extraño y un subordinado" (Bohórquez \& Jaramillo, 2004). Esta relación de distancia no es más que el alejamiento tematizante y objetivo del otro, con el fin de ir a la constatación de un saber que se ha previsto de antemano; como consecuencia, en medicina se aprende lo desconocido del otro, paciente, con la ayuda de lo conocido o saber médico del mismo. Frente a esta negación del otro, veamos a continuación cómo el filósofo Emmanuel Levinas propone una apertura ética del Otro, desde el mundo de la vida en la relación médico-paciente (advertimos que estas temáticas no son exclusividad del pensamiento de Levinas; ver al respecto los trabajos de Canguilhem, 1982). Posición que está en correspondencia con otros autores, como Thoresen et al. (2011), quienes consideran que el mundo de la vida puede ayudar a los profesionales a ser conscientes de las dimensiones significativas y relevantes que vivencian las personas que están cercanas a la experiencia de la muerte.

\section{EL MUNDO DE LA VIDA COMO APERTURA A UNA RELACIÓN ÉTICA MÉDICO-PACIENTE. Antes de} presentar las líneas generales del pensamiento de Levinas es necesario hacer la siguiente salvedad: se ha dicho que más que Fenomenología existen fenomenologías (Herrera, 2007; Aguirre \& Jaramillo, 2009); en el caso de Levinas, la ruptura con la ortodoxia husserliana intentó enmarcarla en su propuesta de la conciencia no-intencional. En el artículo "La conciencia no-intencional" (Levinas, 1991), el autor refina su posición con respecto a la intencionalidad husserliana, destacando que ella es una deuda que tiene con Husserl; para Levinas, el gran aporte de la fenomenología consiste en que "lo pensado -objeto, tema, sentido- remite al pensamiento que lo piensa, pero determina también la articulación subjetiva de su aparecer: el ser determina sus fenómenos" (Levinas, 2004); esto anuncia una nueva forma de desarrollar conceptos no reducida a lo empírico ni a deducciones analíticas, sintéticas o dialécticas.

Reconocida su deuda con el fundador de la fenomenología y expuesto su aporte en el proceso del conocimiento, Levinas pasa a cuestionar las tesis husserlianas, a las que acusa de privilegiar lo teorético, es decir, la representación, el saber, el sentido ontológico del ser (una crítica similar, se puede encontrar en Sartre, 2003). Levinas ve en la consideración husserliana de la "intencionalidad no teórica", en el Lebenswelt, incluso en los análisis del cuerpo ampliamente desarrollados por otros autores, como Merleau-Ponty (1976), vanos intentos por salir de la esfera teorética del marco de la experiencia, pues esta intencionalidad mentalista propone sustituir el ser por la conciencia, trasformando el "en sí" del mundo por la objetividad de un mundo dado para el sujeto, a partir de sus representaciones (Gaitán, 2010).

Para Levinas, Husserl (1995) coloca la intencionalidad como a priori de todo conocimiento teorizante; aquí la conciencia es punto de partida, en tanto es conciencia de... e inseparable del objeto intencional. De este modo, el objeto se presenta como re-presentación de todo acto objetivante, siendo para la misma conciencia objeto de... Husserl (1995) a través de la intencionalidad, invita a que nos preguntemos hacia dónde tiende la conciencia, dándose una tematización del otro, en el orden fenoménico del aparecer.

Por consiguiente, Levinas sintetiza sus críticas contra lo que para la tradición filosófica es la fuente de sentido, a través de los siguientes planteamientos: la correlación conocimiento y ser: "la correlación conocimiento-ser, la temática de la contemplación, significa una diferencia y, a la vez, una diferencia sobrepasada en lo verdadero donde lo conocido es comprendido y, de este modo, apropiado por el saber y como eximido de su alteridad" (Levinas, 2006). Para Levinas, lo único que podría romper lo teorético sería la relación con el otro, la cual, no se puede dar plenamente sino en el marco de la conciencia no-intencional; precisamente, se pregunta si el pensamiento, entendido como saber desde la ontología de la filosofía primera, agota los posibles de la significancia del pensamiento y si, tras el saber y su dominio sobre el ser, no surge una sabiduría más urgente.

Para responder esta pregunta, Levinas (2004) establecerá la distinción entre la conciencia intencional y la conciencia no reflexiva o pre-reflexiva y se preguntará: "¿Sabe en sentido estricto el "saber» de la conciencia pre-reflexiva?" Esta conciencia pre-reflexiva será un saber que, lejos de anclarse en la claridad y en la distinción, se debe comprender como 
un desvanecimiento u ocultamiento de la presencia. Levinas denominará esta conciencia pre-reflexiva mala conciencia, caracterizada por carecer de intenciones, enfoques, nombre, situación, títulos; determinada por estar desnuda de todo atributo; desnudez que no se consigue a partir del develamiento o el descubrimiento de su verdad (en Totalidad e Infinito dirá: verdad plena que sólo puede brotar de la revelación); conciencia pre-reflexiva que, lejos de ser actividad del yo puedo, brota de la pasividad: "en la pasividad de lo no-intencional se pone en cuestión la justicia misma de la posición en el ser que se afirma en el pensamiento intencional, saber y dominio de la manu-tención: ser como mala conciencia; estar en cuestión, pero también ser interrogado, tener que responder: nacimiento del lenguaje".

Sin embargo, esta respuesta no se puede dar en el tribunal del psiquismo como un ejercicio de autocrítica en el que, el pensador, siempre apoyado en alguna argucia, saldría bien librado. Tener que responder nos sitúa en lo más exterior, en lo que no se deja reducir, debido a su infinitud, a mi interioridad; la respuesta no se da a una ley anónima sino al temor por los demás: "Temor por todo aquello que mi existir, a pesar de su inocencia intencional y consciente, puede representar de violencia y muerte. Temor que se remonta más allá de mi «conciencia de sí», por muy fuerte que sea la recuperación de la buena conciencia de la pura perseverancia en el ser. Temor que me llega desde el rostro del Otro (Autrui). Rectitud extrema del rostro del prójimo que desgarra las formas plásticas del fenómeno. Rectitud de una exposición a la muerte, sin defensa; $\mathrm{y}$, antes de todo lenguaje y de toda mímica, una demanda que se dirige a mí desde el fondo de una soledad absoluta; una llamada o una orden, cuestionamiento de mi presencia y de mi responsabilidad" (Levinas, 2004).

En este párrafo, que bien se podría considerar como la condensación de toda la búsqueda levinasiana, se pueden entrever las críticas a la conciencia representacional: en primer lugar, sólo la presencia del otro, absolutamente Otro, da pleno sentido al concepto de verdad, en la medida en que el otro jamás podrá ser reducido al mismo (representado, intencionado); en segundo lugar, más que adoptar posturas comprensivas frente al otro, lo que lo ubicaría en el plano de la tematización, el Otro exige respuesta, actitud que sólo se puede entender en la esfera de lo pre-reflexivo; finalmente, si el acceso al Otro se da en términos de lenguaje, éste no será retórica que pretenda algo, asentimiento o persuasión, ni texto, obra (pues el decir jamás podrá encerrarse en lo dicho) sino en exposición (Aguirre \& Jaramillo, 2010b). Respecto a la relación médico-paciente podríamos decir que el Otroenfermo no es el constituido a la conciencia de un profesional de la salud que puede pre-decir su patología o lesión orgánica por su representación teórica que se tiene de la enfermedad; por el contrario, el Otro-enfermo se remonta a una vulnerabilidad y desnudez que pone en cuestión el saber del experto, al instalarse, más bien, al remontarse por encima del campo de una conciencia fenomenológica. El paciente, a pesar de su padecer, se retrae a la correlación ser-saber porque demanda un llamado al saber-experto del médico; llamado a la responsabilidad por el destello de su rostro; rostro-paciente que se revela/rebela -por su vulnerabilidad- como prójimo, el cual, no se puede comprender sólo desde análisis de laboratorio o anamnesis impersonales sino en un plano eminentemente ético (Clifton-Soderstrom, 2003; Carel, 2011).

Lamentablemente, los procesos de relación médico-paciente se han caracterizado por una relación que engloba el saber del paciente en la totalidad omni-comprensiva del médico, ligado a la formación que éste ha tenido en los claustros universitarios, donde se va arropando su mundo vital o cotidiano por el mundo teórico de la medicina. En este sentido, para el médico, su formación es un conocer más desde su profesión como capacitación que como formación, que llama a un encuentro con el Otro: hay una escisión en la educación médica que disocia capacitación y formación, sobrevalorando la capacitación y desconociendo la formación; así, el médico tiende a anteponer su rol profesional al ser personal, por tanto, subroga su ser al proceder, al enfatizarse la formación en la capacitación, es valorada desde una racionalidad técnica y a intereses profesionales; como consecuencia, se subvaloran los sujetos que participan en ella y al contexto (Bohórquez \& Jaramillo, 2004) .

Anteponer capacitación a formación es reducir al médico a sujeto-productor de un saber que lo faculta sobre un sujeto que padece y necesita de su predicción anatómico-funcional; saber que se aleja del encuentro ético de la responsabilidad y la capacitación como ejercicio de poder-médico que ubica en la correlación padecer-conocer, y que hace del médico un ser que comprende en la soledad del encuentro con el otro que sufre; paciente que toca desde un diagnóstico, pero que ignora en la indefensión de su rostro. Por consiguiente, o bien el médico sigue tratando al otro (paciente-objeto) como fuente de datos o lo asume como Otro al abordarlo desde el infinito de su desnudez en el padecimiento y en el dolor de su enfermedad; sólo podemos ver el infinito del otro que sufre cuando lo asumimos como radicalmente Otro (Jaramillo et al. 2004), pretensión que se intentará en el siguiente apartado.

\section{SUFRIMIENTO, DOLOR E IRREDUCTIBILIDAD EN LA} RELACIÓN MÉDICO-PACIENTE. El sufrimiento desborda toda contención de la conciencia intencional; sin embargo, se podría intentar ver el sentido del sufrimiento apelando a una razón explicativa: "Ya en el interior de una conciencia aislada, el dolor de sufrir puede adquirir el sentido de una pena que merece y espera un salario, y parece perder así de diversos modos su modalidad de inútil" (Levinas, 1993). En 
el plano individual, el sufrimiento templaría el carácter o, al menos, serviría como indicador fisiológico, un síntoma que alerta de los peligros de una enfermedad. En el plano social, el sufrimiento de una comunidad permite llamados de atención que se deben suplir en pro del bienestar del cuerpo colectivo; en este caso, la utilidad del sufrimiento sería recogida por el poder para que, de modo pedagógico, emprendiera acciones de formación, de dirección y de represión. Asumiendo razones personales o sociales, el sufrimiento adquiere un sentido: "es esta, en verdad, una teleología política fundada en el valor de la existencia, en la perseverancia de la sociedad y del individuo en el ser, en su bienestar admitido como fin último y supremo" (Levinas, 1993).

La búsqueda del sentido del sin-sentido del sufrimiento es nominada por Levinas como Teodicea; en este caso, el sufrimiento se torna "un dolor que por tanto tiene sentido, que está subordinado de una u otra forma a la finalidad metafísica adivinada por la fe o por la creencia en el progreso. iCreencias todas ellas presupuestas por la teodicea! Esta es la gran idea necesaria para la paz interior de las almas en nuestro aquejado mundo. La invocamos para hacer comprensibles los sufrimientos de este mundo" (Levinas, 1993). El sentido, en este caso, fundaría un orden justo que comprende y tolera el sufrimiento, merced a su función depuradora para lograr el Bien, siempre y cuando los derechos del hombre aún se preserven, es decir, hasta el sufrimiento queda regulado y adquiere un estatus dentro del orden establecido; sin embargo, ċcómo justificar el dolor de otro?, ¿cómo solicitarle que encuentre un sentido, así sea persuadiéndolo con los más nobles ideales? En este punto Levinas concluye que "la justificación del dolor del prójimo es ciertamente el origen de toda inmoralidad" (Levinas, 1993; Aguirre, 2010).

Si algo reclama Levinas en su filosofía es la inaplazable urgencia del rostro concreto del otro, en especial del desplazado, de la viuda, del enfermo; rostros tan fáciles de abstraer en la totalidad y de situarlos en categorías asépticas (Jaramillo \& Aguirre, 2010), por tanto, en vez de hablar del dolor, del sufrimiento, situémonos en el caso concreto de la relación médico-paciente y, a partir de lo considerado, tanto por Husserl sobre el mundo de la vida como por la Ética de Levinas, encontremos modos concretos de asumir una ética de la vida. Para esto, nos apoyaremos en algunas investigaciones del profesor Stan van Hooft, de la Universidad de Deakin, Australia (aunque podríamos citar trabajos más recientes como, por ejemplo, los de Orange, 2011). Para Hooft (1998), "el sufrimiento es una de las experiencias humanas más profundas y perturbadoras. La misma palabra sufrimiento tiene una resonancia que se relaciona con el sentido que damos al significado de nuestra vida y con la amenaza que lanza el sufrimiento a nuestro afán de felicidad". Ahora bien, el sufrimiento no sólo se relaciona con las enfermedades, los dolores y las dificultades a las que debemos enfrentarnos; también involucra las crisis y las amenazas, que constituyen una degradación o alienación de nuestro propio ser; Wolcher (2003) plantea, en términos levinasianos, que el sufrimiento no admite justificaciones en tanto está más allá del ser; sin embargo, es en los primeros casos en los que palpamos, de manera más urgente y cotidiana, bajo las formas del dolor, cómo el sufrimiento del enfermo interrumpe la estabilidad de su vivir.

El alivio del dolor es considerado una disciplina científica administrada por expertos basados en consideraciones objetivas, más que en las necesidades y deseos de los pacientes. Quizá una de las causas para esta aproximación es que el dolor es asumido como algo no directamente comunicable; como resultado, los clínicos deben usar un modo de juzgar que brota de un diagnóstico objetivo; los tratamientos que prescriben, se basan sólo en tales juicios, más que en la comunicación del dolor por parte del paciente (Hooft, 2003). La cuestión primordial aquí es que si el dolor se enfoca, desde Levinas, como algo que no se puede tematizar, como propio de la esfera no-intencional, ccómo hace el médico para comprender el dolor del paciente, cómo hace éste para expresar su dolor? En este sentido, el problema se ubica en la comunicabilidad del dolor.

La definición de dolor, que asume Hooft, es la siguiente: "una experiencia sensorial y emocional asociada con daño actual o potencial de un tejido o descrita en términos de tal daño" (Hooft, 2003). Esta definición subraya varios aspectos: en primer lugar, el carácter desagradable del dolor: preferiríamos estar sin dolor; en segundo lugar, que el dolor es una experiencia: no tendría sentido decir que una persona tiene un dolor pero que no lo siente; en tercer lugar, la definición apunta al cuerpo: el dolor siempre es sentido como si estuviera localizado en una porción específica del cuerpo, es decir, "parece que a todo dolor le acompaña una experiencia física" o, dicho en otras palabras, "no resulta posible pensar el dolor sin un acompañante físico" (Vargas, 2005). En cuarto lugar, el dolor es una experiencia sensible: no se quiere decir que se vea o se toque, lo que se quiere enfatizar es que el dolor es sentido y experimentado en el cuerpo más que en el pensamiento. Finalmente, el dolor es una experiencia emocional: reaccionamos negativamente frente a él (Hooft, 2003).

Se puede considerar ahora otra idea agregada al concepto de dolor: su carácter de privacidad. Como modo de la subjetividad, el dolor es intensamente privado, es decir, es radicalmente mío; no existe objetivación que pueda permitirle al otro compartir mi dolor. Es tal vez esa la característica que haga difícil al médico aproximarse a mi dolor; a lo sumo 
podrán comprender que el dolor que tengo es un llamado a una respuesta médica; sin embargo, si hemos partido de la premisa que el dolor es intensamente privado, ċcómo es posible una respuesta?

Hooft cita a este respecto una frase de Virginia Wolf: "El inglés que puede expresar los pensamientos de Hamlet y la tragedia de Lear no tiene palabras para el escalofrío o el dolor de cabeza" (Hooft, 2003). A lo sumo, las palabras nos transmiten metáforas del dolor sentido; de ahí se concluiría, seguramente también Wolf, que el dolor no se puede transmitir en un lenguaje literal, sino que sólo tendríamos un acceso metafórico y, por tanto, impreciso, lo que a la larga implicaría un desconocimiento; no obstante, tal desconfianza con respecto a la metáfora carece de justificación: cacaso no es usual que describamos metafóricamente nuestras experiencias?, cla experiencia que tengo de disfrutar un hermoso atardecer no se puede compartir? Si bien mi descripción puede que no salga tan poética o metafórica como yo la percibo, puedo comunicar la mayoría de mi sentimiento con relación a ese atardecer.

Hooft se pregunta si esto no sucede igual con el dolor. Éste hace mención al cuestionario del dolor de McGill, desarrollado por Melzack \& Torgerson (1971), el cual, "explora las connotaciones, relaciones, contrastes y similitudes entre las metáforas usadas al describir el dolor y sus relaciones con las enfermedades actuales". Con esto quedaría desvirtuado el hecho que el dolor es incomunicable. Ahora bien, pongamos un caso extremo, dolores que ni siquiera pueden dar alguna articulación metafórica; un dolor expresado en gemidos o llanto. Concluye Hooft que, pese a que ese lenguaje es incapaz de articularse verbalmente, esto no significa que no pueda articularse de ningún modo (Hooft, 2003).

Pero lo que en la actitud natural se puede ver tan fácil de subsanar, en la actitud filosófica plantea serias cuestiones a la comunicabilidad del dolor: en primer lugar, el dolor es nointencional: "Yo puedo describir mi ira al decir lo que me molestó. Puedo describir mi miedo al decir lo que me atemorizaba. Pero no puedo describir mi dolor de este modo. Puedo referirme a esa parte de mi cuerpo en la que el dolor está localizado, pero esto no es identificar un objeto intencional de dolor así como su sitio" (Hooft, 2003). En segundo lugar, el dolor derrota al lenguaje, en tanto la función del lenguaje es referirse a objetos; ahora bien, esto se extiende a que en ausencia de objetos a los cuales referirse el lenguaje, se deben recurrir a criterios objetivos para la adscripción de tales términos; así, "debo ser capaz de aplicar el criterio público para adscribir un estado subjetivo a mí mismo del modo en el que he aprendido a adscribírselo a otros" (Hooft, 2003). Ambos argumentos se podrían desvanecer usando un argumento del sentido común: ambas premisas olvidan que la mayoría de nuestras charlas cotidianas no tienen la intención de informarnos acerca del mundo, sino de conservar o crear la intersubjetividad. Introduzcamos, finalmente, otro desafío a la comunicabilidad del dolor: el dolor aísla: "Para quien sufre dolor su mundo se reduce, en proporción a la severidad de su dolor, a su propia y aislada realidad. El mundo cesa de contar para esa persona. No es capaz de olvidarse de sí misma y estar plenamente en contacto con el mundo. Su atención está centrada en sí mismo. Está obsesionado con los estados de su cuerpo. No se trata sólo de que su experiencia es propia o que es incomunicable. No es que no se tengan las palabras para describir su dolor, como algunos sostienen. Es que no se es capaz de escapar de la prisión del auto-envolvimiento que su dolor ha creado a su alrededor. No hay realidad para ellos más que su propio sufrimiento (Hooft, 2003).

Siguiendo a Levinas, Hooft analiza el dolor como un reto ético. Para sustentar su conclusión, parte de las siguientes premisas: a) pese a que en fenómenos cotidianos como, por ejemplo, la conversación, se dan en términos de lenguaje, hay elementos, una mirada, un gesto, un silencio, que no pueden ser leídos como temas; b) el misterio y el infinito del Otro no se pueden asir conceptualmente; c) el Otro siempre es Otro en el sentido radical en que no puede ser apropiado por mí ni en la comprensión ni en la percepción; d) el modo de acceso al Otro es fundamentalmente ético: "si lo clasifico y lo pongo en una categoría predefinida, si me relaciono con él, tal y como lo he estructurado por esa clasificación, entonces actúo sin ética. Si me relaciono con un empleado sólo como un funcionario de mi empresa, o si me relaciono con mi paciente como un problema por resolver, entonces mi comportamiento no es ético" (Hooft, 2003).

Según esto, si bien existen argumentos para demostrar que el dolor es comunicable es más importante considerar que el dolor es radicalmente privado y no se puede compartir; posición planteada por Vargas (2005), cuando considera que "el dolor del otro es experimentado en la posición de la subjetividad como tal y en cuanto tal. El otro, sujeto, me motiva, hesitando mi posibilidad de existencia de estar en su lugar". El dolor es, entonces, un misterio para quien lo observa desde fuera, es parte de la naturaleza incomprensible e infinita del Otro. La razón teórica de esto radica en que, según Hooft (2003), "para mí, tu dolor no es un fenómeno, no es un precepto. Es una modalidad de tu subjetividad, es una condición de tu misterio, de tu otredad, de tu infinitud. Aunque tú me transmitas mucho mediante las cosas que dices, las metáforas que usas o los gestos de tu cuerpo, permaneces en tu dolor. Aún en los niveles más profundos del encuentro, no puedo entenderlo ni clasificarlo. Si lo compartimentalizara como parte de un diagnóstico o tratamiento, no podría tomar posesión de él, ni hacerlo mío”. 
En resumen, el reto ético del que habla Hooft, específicamente, en el caso del paciente, se comprime en que el encuentro del otro como Otro exige reabrir el mundo del paciente y romper su aislamiento al que ha sido forzado por su dolor y que es tematizado, a través de una escala de valores numéricos, llamada umbral de dolor. En el contexto clínico, la empatía o la compasión es la forma de responder a este reto y hacer posible la comunicación de y acerca del dolor. Obviamente, no estamos hablando de una comunicación factual y de información pragmática que lleve a responder a preguntas como: ¿dónde te duele? o cंcómo sientes esto?, estamos hablando del establecimiento de la intersubjetividad, un encuentro entre dos yos.

CONCLUSIÓN: La ética médica frente al dolor en el mundo de la vida. El dolor revela al otro en su vulnerabilidad y desborda las representaciones que el mismo posee en su conciencia; fuera de toda intencionalidad comprehensiva, el dolor del otro-paciente duele al mismo de la medicina desde el infinito de su trascendencia e irreductibilidad. El paciente que sufre, a pesar de su dolencia, no llama a sentir por él una compasión lastimera, ni la conmiseración de querer ocupar su lugar como doliente; tampoco al seudo-altruismo abnegado que se enmascara como caridad. Más allá de cualquier mistificación humanitaria, el médico, en sí mismo, experimentará el dolor desgarrado de no querer apresar al paciente, a través de los roles tipificadores de su conciencia (Jaramillo \& Aguirre, 2010). Ahora bien, tampoco se trata de contrarrestar el dolor del otro haciendo de la insensibilidad e indiferencia de saber que el que sufre es el otro y no el mismo. Por el contrario, tanto en la tipificación del dolor como en su negación; el paciente que sufre demanda e invoca una responsabilidad que obliga al saber médico a sentirlo en la hospitalidad de la acogida. Por ello, quien niega el dolor o lo enmascara no lo hace por las fallas o aciertos del intelecto; más allá de todo psiquismo, será por fallas del espíritu (Das, 2008). Espíritu que revela el grito ensordecedor de un sufrimiento que impide que el paciente, más allá de su dolor físico, padezca también el dolor infinito de su trascendencia; por ello: "quizás lo espiritual no muestre -no revele- su especificidad más que cuando se interrumpe la rutina del ser: en la extrañeza de unos humanos ante los otros, que sin embargo son capaces de una sociedad cuyo vínculo ya no es la integración de las partes en un todo.

Quizás, el vínculo espiritual resida en la no-indiferencia de unos hombres para con los otros que también se llama amor, pero que no reabsorbe la indiferencia de la extrañeza y que no es posible más que a partir de una palabra o de una orden que viene, a través del rostro humano, de muy alto fuera del mundo" (Levinas, 2002).
Quizás, la irreductibilidad del dolor en la relación médicopaciente sea uno de los retos que más debe afrontar el ser humano en el acontecer de su cotidianidad; el quebrantamiento de una humanidad que se hace piel en su dolor y enfermedad está propensa a ser re-absorbida por la representación de la conciencia intencional del saber médico. El recorrido hecho a lo largo de este escrito nos ha permitido entablar diálogo con la propuesta husserliana de la Lebenswelt. El retorno al mundo pre-dado, al mundo no cubierto, aún por el abrigo de la teoría, nos descubre las entreveradas relaciones que se tejen científicamente alrededor del dolor y las justificaciones que brotan acerca de la posibilidad de su comunicación, bien sea en palabras o en gestos, llevando a los especialistas del dolor a confiar en sus diagnósticos. El énfasis puesto por Levinas en la conciencia no-intencional libera al mundo de la vida de las pretensiones teóricas y omnicomprensivas, típicas del naturalismo y sitúa el dolor "de espaldas" a la conciencia. En este sentido, el mundo de la vida es un resituar el olvidado mundo en el que acaece lo auténticamente humano, un descentrar las pretensiones de mathesis universalis que justifican todo a partir de la conjunción conocer-ser y, un entronizar la ética como filosofía primera. Así, en el caso concreto del dolor que sufre un paciente y las relaciones que se tejen con el médico, se puede establecer la prolijidad del mundo de la vida en pro de la cada vez más urgente formulación de la Ética de la vida, permitiendo ampliar las fronteras del cuidado de la salud (Nortvedt, 2003).

Agradecimientos: Los autores desean expresamente dar crédito y mención a la Universidad del Cauca, por brindar los espacios y los tiempos necesarios para madurar las reflexiones aquí consignadas; también queremos agradecer a nuestros colegas de los Departamentos de Filosofía y Educación Física, por las discusiones que se han ido adelantando al interior de estas unidades académicas. Conflicto de intereses: El manuscrito fue preparado y revisado con la participación de todos los autores, quienes declaramos que no existe ningún conflicto de intereses que ponga en riesgo la validez de los resultados esperados. Finalmente, queremos resaltar que algunas ideas contenidas en este trabajo se encuentran en Giraldo \& Aguirre (2009).

\section{BIBLIOGRAFÍA}

1. AGUIRRE, J.C. 2010. Sufrimiento, verdad y justicia. Alpha 30:169-180.

2. AGUIRRE, J.C.; JARAMILLO, L.G. 2010a. La ciencia y el sentido común: por la enseñanza de un sentido común crítico. Educ. Educad. 13(3):477-494. 
3. AGUIRRE, J.C.; JARAMILLO, L.G. 2010b. Críticas de Levinas al primado husserliano de la conciencia intencional". Rev. Filos. 66:51-70.

4. AGUIRRE, J.C.; JARAMILLO, L.G. 2009. La relación entre Merleau-Ponty y Gurwitsch en torno a la fenomenología de Husserl: ćprogreso o ruptura?" Acta Fenomenológica Latinoamericana, Volumen III. México / Lima: Universidad Michoacana de San Nicolás de Hidalgo / Pontificia Universidad Católica del Perú, p.483-498.

5. BOHÓRQUEZ, F.; JARAMILLO, L. 2004. El diálogo como encuentro: aproximación a la relación ética médico-paciente. Hacia la promoción de la salud. 9:79-91.

6. CANGUILHEM, G. 1982. Lo normal y lo patológico. Siglo XXI (México). 242p.

7. CAREL, H. 2011. Phenomenology and Its application in medicine. Theoret. Med. Bioeth. 32(1):33-46.

8. CLIFTON-SODERSTROM, M. 2003. Levinas and Patient as Other: The Ethical Foundation of Medicine. J. Med. \& Philos. 28(4):447-460.

9. DAS, V. 2008. Lenguaje y Cuerpo: transacciones en la construcción del dolor. Ortega, F. (ed.). Sujetos del dolor, agentes de dignidad. Bogotá: Universidad Nacional de Colombia. p.343-374.

10. GADAMER, H.G. 1993. Verdad y Método I. Sígueme (Salamanca). 697p.

11. GADAMER, H.G. 1996. El estado oculto de la salud. Gedisa (Barcelona). 192p.

12. GAITÁN, C. 2010. Sentido de la epistemología en las Ciencias Sociales. Itinerantes. 5:10-17.

13. GIRALDO, J.; AGUIRRE, J. 2009. Mundo de la vida y ética de la vida. Asedios fenomenológicos II. Mundo de la vida y ciencias humanas. Universidad del Cauca (Popayán). p.1-21.

14. HABERMAS, J. 1987 Teoría de la Acción Comunicativa I. Taurus (Madrid). 520p.

15. HERRERA, D. 2007. "Fenomenología". Jesús Antonio Serrano Sánchez (comp.) Filosofía actual en perspectiva latinoamericana. Bogotá: San Pablo. p.19-46.
16. HOOFT, S. 1998. The Meanings of Suffering. The Hastings Center Report. 28(5):13-19.

17. HOOFT, S. 2003. Pain and Communication. Med., Health Care Philos. 6:255-262.

18. HUSSERL, E. 1980. Experiencia y Juicio: investigaciones acerca de la genealogía de la lógica (redacción y edición de Ludwig Langrebe) UNAM (México). 482p.

19. HUSSERL, E. 1995. Investigaciones Lógicas. Volumen II. Altaya (Madrid). 777p.

20. HUSSERL, E. 2008a. Crisis de las ciencias europeas y la fenomenología trascendental. Prometeo (Buenos Aires). 304p.

21. HUSSERL, E. 2008b. Die Lebenswelt. Auslegungen der vorgegebenen Welt und ihrer Konstitution. Texte aus dem Nachlass (1916-1937). Springer (Dordrecht). 1044p.

22. IRIBARNE, J. 2008. Estudio Preliminar. Husserl, E. Crisis de las ciencias europeas y la fenomenología trascendental. Prometeo (Buenos Aires). 304p.

23. JARAMILLO L.G.; AGUIRRE, J.C. 2010. Rostro y alteridad: de la presencia plástica a la desnudez ética. Rev. Latinoam. Cienc. Soc., Niñez y Juv. 8(1):175188.

24. JARAMILLO, L.G.; PINILLA, C.A.; DUQUE, M.I.; GONZÁLEZ, L. 2004. Percepción del paciente y su relación comunicativa con el personal de la salud en el servicio de agudos del Hospital de Caldas. Index Enf. 46:29-33.

25. LEVINAS, E. 2006. Ética como filosofía primera. A parte rei, 43:1-21.

26. LEVINAS, E. 2004. Entre nous. Le livre de poche (Paris). 252p.

27. LEVINAS, E. 2002. Fuera del sujeto. Caparrós (Madrid). 172p.

28. LEVINAS, E. 1993. Entre Nosotros; ensayos para pensar en otro. Pre-textos (Valencia). 289p.

29. LEVINAS, E. 1991. La Conscience non-intentionnelle. Entre-nous: Essais sur le penser-à-l'autre (Paris). 150p. 
30. MAFFESOLI, M. 1993. El conocimiento ordinario: compendio de sociología. Fondo de Cultura Económica (México). 216p.

31. MAFFESOLI, M. 1997. Elogio de la razón sensible. Paidós (Barcelona). 270p.

32. MELZACK, R.; TORGERSON, W. 1971. On the language of pain. Anesthesiol. 34:50-59.

33. MERLEAU-PONTY, M. 1976. Phénoménologie de la Perception. Gallimard (Paris). 531p.

34. NORTVEDT, P. 2003. Levinas, justice and health care. Med., Health Care Philos. 6:25-34.

35. ORANGE, D. 2011. The suffering stranger. Hermeneutics for Everyday Clinical Practice. Routledge (New York). 267p.

36. SAN MARTÍN, J. 2010. El pluralismo desde la "razón" fenomenológica. Anuario Colombiano de Fenomenología, Volumen IV. Universidad del Cauca (Popayán). p.263-274.

37. SARTRE, J.P. 2003. La trascendencia del ego: esbozo de una descripción fenomenológica. Síntesis (Madrid). $111 \mathrm{p}$.
38. STRÖKER, E. 1997. The Husserlian foundations of Science. Kluwer Academic Publishers (Dordrecht). 304p.

39. THORESEN, L.; WYLLER, T.; HEGGEN, K. 2011. The significance of lifeworld and the case of hospice. Med., Health Care Philos. 14(3):257-263.

40. VARGAS, G. 2005. Descripción fenomenológica del dolor de la experiencia intropática del dolor. En: Vargas, G. (ed.) Fenomenología y Literatura. Universidad Pedagógica Nacional (Bogotá). p.99108.

41. WALTON, R. 1993. Husserl, mundo, conciencia y temporalidad. Almagesto (Buenos Aires). 193p.

42. WOLCHER, L. 2003. Ethics, justice, and suffering in the thought of Levinas: the problem of the passage. Law Critique. 14:93-116.

Recibido: Septiembre 29 de 2011

Aceptado: Marzo 1 de 2012 